\title{
Wait Times Experienced by Lung Cancer Patients in the BC Southern Interior to Obtain Oncologic Care: Exploration of the Intervals from First Abnormal Imaging to Oncologic Treatment
}

\author{
David Van de Vosse ${ }^{1}$, Rezwan Chowdhury ${ }^{1}$, Andrew Boyce ${ }^{1}$, Ross Halperin ${ }^{1}$ \\ 1. Department of Radiation Oncology, BC Cancer Agency, Sindi Ahluwalia Hawkins Centre for the Southern Interior
}

$\square$ Corresponding author: David Van de Vosse, dwv@ualberta.ca

Disclosures can be found in Additional Information at the end of the article

\begin{abstract}
Background: Lung cancer is associated with rapid disease progression, which can significantly progress over a duration of four to eight weeks. This study examines the time interval lung cancer patients from the interior of British Columbia (BC) experience while undergoing diagnostic evaluation, biopsy, staging, and preparation for treatment.
\end{abstract}

Methods: A chart review of lung cancer patients $(\mathrm{n}=231$ ) referred to the BC Cancer Agency Centre for the Southern Interior between January 1, 2010 and December 31, 2011 was performed. Time zero was defined as the date of the first abnormal chest imaging. Time intervals, expressed as median averages, to specialist consult, biopsy, oncologic referral, initial oncology consultation, and commencement of oncologic treatment were obtained.

Results: The median time interval from first abnormal chest imaging to a specialist consultation was 18 days (interquartile range, IQR, 7-36). An additional nine days elapsed prior to biopsy in the form of bronchoscopy, CT-guided biopsy, or sputum cytology (median; IQR, 3-21); if lobectomy was required, 18 days elapsed (median; IQR, 9-28). Eight days were required for pathologic diagnosis and subsequent referral to the cancer centre (median; IQR, 3-16.5). Once referral was received, 10 days elapsed prior to consultation with either a medical or radiation oncologist (median, IQR 5-18). Finally, eight days was required for initiation of radiation and/or chemotherapy (median; IQR, 1-15). The median wait time from detection of lung cancer on imaging to oncologic treatment in the form of radiation and/or chemotherapy was 65.5 days (IQR, 41.5104.3).

Interpretation: Patients in the BC Southern Interior experience considerable delays in accessing lung cancer care. During this time, the disease has the potential to significantly progress and it is possible that a subset of patients may lose their opportunity for curative intent treatment.

Received 08/05/2015

Review began 08/14/2015

Review ended 09/01/2015

Published 09/22/2015

(๑) Copyright 2015

Van de Vosse et al. This is an open access article distributed under the terms of the Creative Commons Attribution License CCBY 3.0., which permits unrestricted use, distribution, and reproduction in any medium, provided the original author and source are credited.
Categories: Oncology, Quality Improvement, Radiation Oncology

Keywords: lung cancer, time interval, wait time, outcomes

\section{Introduction}

Lung cancer represents a significant cause of morbidity and mortality in the province of British Columbia. Despite having the lowest mortality rates of lung cancer within Canada (BC, 38.1 per 100,000), the overall age-standardized five-year survival for lung cancer in $\mathrm{BC}$ is below the national average (BC, $16.9 \%$, Canada, 18.4\%) [1]. Albeit, this is similar to the United States (17.8\%) and greater than the European average (13\%) [2-3]. Accordingly, of the nearly 3,000 new lung cancer diagnoses in BC each year, approximately 2,250 deaths occur [4]. Overall, deaths attributable to lung cancer are greater than that of the next three leading causes (colorectal, breast, and prostate carcinomas) of cancer-related deaths combined [4]. The high mortality rate has been attributed to, among others, a late stage of disease presentation at the time of diagnosis and the rapid progression of lung cancer [5-6]. For instance, small-cell lung cancer exhibits a tumor-doubling time as rapid as 30 days (d) [6-7], suggesting that any delay between onset of symptoms, diagnosis, and oncologic treatment has the potential for significant disease progression and may preclude a subset of patients to lose their opportunity for curative intent [8-9]. If significant delays in care exist, a key strategy for improving outcomes would be to reduce the time interval lung cancer patients experience. Reducing wait times may be easier, and possibly more economically viable, than developing new drugs and treatments to delay or reverse disease course once it has advanced.

Determination of timelines of care for lung cancer patients globally has revealed considerable variability 
[10-24]. For instance, in the United States, time intervals from initial abnormal radiograph to treatment initiation vary from 35 to $84 \mathrm{~d}$ [14, 16-17, 20]. While relatively few studies have been performed regarding lung cancer wait times within Canada [21-24], one prospective study in Ontario reported a median time interval from development of first symptoms to initiation of treatment of $138 \mathrm{~d}$ [23], while another study from Manitoba reported a median of $145 \mathrm{~d}$ from first physician visit to diagnosis [22]. Such differences in time intervals among various centres highlight the need for individual centres to perform internal quality assurance studies to identify avoidable delays in treatment.

The vast majority of studies examining lung cancer wait times have been conducted at centres servicing dense, urban municipalities. As a result, data on time intervals experienced by rural patients are lacking. The BC Cancer Agency Centre for the Southern Interior (BCCA-CSI) is distinct in that it services both urban and remote rural populations. Its catchment population of $\sim 750,000$ is distributed over an area approximately the size of the United Kingdom [25-26], stretching from the Alberta border to the east, the Fraser Valley to the west, Quesnel to the north, and the United States border to the south. Consequently, nearly one out of five patients must travel more than $300 \mathrm{~km}$ to access oncologic care, with some patients travelling up to 700 $\mathrm{km}$. Considering the recent 2013 Organization for Economic Cooperation and Development (OECD) health report determined Canada has the third highest rate of lung cancer mortality among women in the developed world (47 per 100,000), almost double the OECD average (26.5 per 100,000) [27], a question arises whether this number is partly due to the performance of our health care system, and whether geographic distribution plays a significant role. In light of these considerations, we evaluated the time interval experienced by lung cancer patients referred to the BCCA-CSI. Our study provides data relating to wait times experienced by lung cancer patients outside of the traditionally studied metropolitan centres and provides evidence for a focused and detailed redesign of the cancer care pathway with emphasis on reducing delays at all stages of lung cancer management.

\section{Materials And Methods}

\section{Study design}

A retrospective chart review was conducted of newly diagnosed lung cancer cases referred to a regional cancer centre (BCCA-CSI) serving both urban and rural communities within the Southern Interior of British Columbia. Data from 713 patients, referred over a two-year period (January 1, 2010 to December 31, 2011), were obtained from the BC Cancer Agency, Data Requests-Surveillance and Outcomes and supplemented by chart review of available electronic medical records accessed via Cancer Agency Information System (CAIS) software (BCCA-EMR). For each case, information was collected on date and type of diagnostic imaging; date and type of specialist consult; date and type of biopsy; histology and staging of disease; date of lobectomy, if applicable; date of referral to BCCA-CSI; date and type of oncologic consult; date and type of oncologic treatment; intent of treatment; date of death; and finally, the Health Service Delivery Area (HSDA) accessed.

This study was submitted to and approved by the British Columbia Cancer Agency's research ethics review board (approval \#H13-02129). Informed patient consent was obtained at the time of treatment.

\section{Primary outcomes and study population}

The primary goal of this study was to determine time intervals between each of the following sequential chart entries: first abnormal diagnostic image, specialist consult (thoracic surgery, respirology, or other specialty), biopsy, referral to BCCA-CSI, oncology consultation (radiation or medical), and initiation of treatment (chemotherapy and/or radiation therapy). Time intervals were further divided on the basis of treatment intent, either curative or palliative, as charted by an oncologist, or distance from primary residence to BCCA-CSI. For cases to be included in this study, charts were required to contain dates for the following entries: initial abnormal diagnostic imaging, biopsy, specialist consult, referral to BCCA-CSI, oncologic consult, and treatment initiation. The typical lung cancer care path was defined as an abnormal diagnostic imaging result, followed by specialist consultation, biopsy, referral to BCCA-CSI, and oncologist consultation, and finally, treatment commencement. Certain groups of patients were excluded in five steps: 1) those with recurrent lung cancer, 2) those who did not follow the typical lung cancer care path, including requiring a second biopsy, 3) those who received care outside of the Southern Interior, or who voluntarily cancelled/delayed a scheduled appointment, 4) those with comorbidities or concurrent cancers deemed to significantly alter the typical treatment care path due to additional consultations and/or tests, and lastly, 5) those lacking information on one or more of the required dates. See Table 1 for additional exclusion criteria. 


\section{Cureus}

\section{Exclusion Criteria}

Recurrent lung cancer

Non-typical cancer care path

Biopsy after referral

$>2$ biopsies

Health care accessed outside of the health authority

Patient delay following abnormal diagnostic image

Patient delay following diagnosis

Significant comorbidity

Concurrent cancer

Death

Missing Information Regarding:

Diagnostic imaging

Biopsy

Referral to cancer centre

\section{Number of Patients}

\section{9}

15

50

19

31

25

38

17

19

22

23

15

TABLE 1: Patient exclusion criteria

Time Intervals Examined

Ti-One Abnormal diagnostic imaging to specialist consult

Ti-Two Specialist consult to biopsy

Ti-Three-A Biopsy to cancer centre referral

Ti-Three-B Biopsy to lobectomy, if required

Ti-Four Cancer centre referral to oncologic consult

Ti-Five Oncologic consult to first treatment

Ti-Six Total time interval from abnormal image to first treatment

TABLE 2: Time intervals examined 


\section{Cureus}

\section{Results}

\section{Clinicopathologic characteristics}

During the two-year study period, 713 newly diagnosed lung cancer patients were referred to the BCCA-CSI. Of these, 231 and 158 cases met our criteria for further analysis of the time interval experienced by lung cancer patients following the standard and alternative care pathways, respectively. Patient demographics for both care pathways are listed in Table 3. Age and gender data were not collected.

\begin{tabular}{|c|c|c|c|c|}
\hline \multirow[b]{2}{*}{ Variable } & \multicolumn{2}{|c|}{ Standard Care Pathway } & \multicolumn{2}{|c|}{ Alternative Care Pathway } \\
\hline & $\mathrm{n}=\mathbf{2 3 1}$ & $\%$ & $n=140$ & $\%$ \\
\hline \multicolumn{5}{|l|}{ Health Service Delivery Area } \\
\hline Okanagan & 137 & 59.3 & 66 & 47.1 \\
\hline Thompson-Cariboo & 42 & 18.2 & 33 & 23.6 \\
\hline Kootenay Boundary & 31 & 13.4 & 14 & 10.0 \\
\hline Northern Interior & 6 & 2.6 & 5 & 3.6 \\
\hline East Kootenay & 5 & 2.2 & 17 & 12.1 \\
\hline Northeast & 1 & 0.4 & 1 & 0.7 \\
\hline Fraser East & 1 & 0.4 & 1 & 0.7 \\
\hline Unspecified & 8 & 3.5 & 3 & 2.1 \\
\hline \multicolumn{5}{|l|}{ Specialist Consultation } \\
\hline Thoracic & 99 & 42.9 & - & - \\
\hline Respirology in Kelowna & 68 & 29.4 & - & - \\
\hline Respirology outside Kelowna & 38 & 16.5 & - & - \\
\hline Other (Int. Med., Neuro Surg.) & 26 & 11.3 & - & - \\
\hline \multicolumn{5}{|l|}{ Biopsy } \\
\hline Bronchoscopy & 141 & 61.0 & 62 & 44.3 \\
\hline CT-guided & 47 & 20.3 & 45 & 32.1 \\
\hline Fine needle aspiration & 24 & 10.4 & 24 & 17.1 \\
\hline Thoracentesis & 4 & 1.7 & 2 & 1.4 \\
\hline Mediastinoscopy & 4 & 1.7 & - & - \\
\hline Sputum & 3 & 1.3 & 3 & 2.1 \\
\hline Craniotomy & 3 & 1.3 & - & - \\
\hline PET & 2 & 0.9 & - & - \\
\hline Laminectomy & 1 & 0.4 & - & - \\
\hline Lobectomy & 1 & 0.4 & - & - \\
\hline Metastasis & 1 & 0.4 & 4 & 2.9 \\
\hline \multicolumn{5}{|l|}{ Histology } \\
\hline NSCLC & 177 & 76.6 & 107 & 76.4 \\
\hline SCLC & 48 & 20.8 & 20 & 14.3 \\
\hline Mesothelioma & 5 & 2.2 & 3 & 2.1 \\
\hline Unspecified & 1 & 0.4 & 10 & 7.1 \\
\hline
\end{tabular}




\section{Cureus}

\section{Staging}

IA

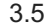

9

6.4

IB

11

4.8

2

1.4

IIA

11

4.8

6

4.3

IIB

7

3.0

6

4.3

IIIA

33

IIIB

14.3

25

17.9

IIB

68

9.5

14

IV

68

Limited stage SCLC

10

29.4

55

Extensive stage SCLC

28

4.3

7

5.0

Unknown

33

12.1

4

2.9

14.3

12

8.6

\section{Treatment Intent}

Curative

58

36

Palliative

173

74.9

104

74.3

TABLE 3: Patient demographics

Approximately half of patients, regardless of the care pathway, accessed care in the Okanagan HSDA, encompassing the urban municipalities of the Okanagan Valley: Kelowna, Penticton, and Vernon. Approximately one-quarter of patients accessed care in the Thompson-Cariboo HSDA, comprising the city of Kamloops and surrounding rural communities, containing both urban and rural patients. The remaining patients accessed care in HSDAs consisting predominantly of small, rural communities.

Following abnormal diagnostic evaluation, referral to a thoracic specialist was the most frequent consultation (42.9\%) and referral to a respirologist within Kelowna the second most frequent (29.4\%). A small cohort (11.3\%) of patients received a specialist consultation outside of respirology or thoracic surgery, predominantly in internal medicine or neurosurgery.

Bronchoscopy was the most common form of biopsy ( $61 \%$ of standard care pathway: $44 \%$ alternative care pathway), followed by CT-guided biopsy (20.3\% and $32.1 \%$ ), and fine needle aspiration (10.4\% and $17.1 \%$ ), in the standard and alternative care pathways, respectively. Histologically, the two pathways were similar with the vast majority of patients diagnosed with non-small cell lung carcinoma (NSCLC, 76\%) most of whom, in agreement with previous studies, had advanced disease (Stage III or greater) [5]. However, the alternative care pathway had a higher incidence of unspecified histology (7.1\% compared to $0.4 \%$ ) and a lower rate of small cell lung carcinoma (SCLC) at $14.3 \%$ versus $20.8 \%$.

Interestingly, individuals within the alternative pathway who bypassed a specialist consultation following abnormal diagnostic imaging were more likely to be diagnosed with either early stage (Stage 1A; 6.4\% alternative pathway versus 3.5\% standard pathway) or late stage of disease (Stage IV; 39.3\% versus $29.4 \%$ ) than the standard care pathway. These results are consistent with a practice in which patients presenting with symptoms of advanced disease are expedited in order to obtain palliative treatment. Similarly, patients presenting with localized, early stages of disease with a significant chance of curative intent may also be expedited. Despite this, however, the percentage of patients receiving treatment with curative intent was almost identical between the two pathways ( $25.1 \%$ standard; $25.7 \%$ non-standard).

\section{Time intervals}

For each time interval, the median, mean, interquartile range, $90^{\text {th }}$ percentile, and range of values are presented in Tables 4 and 5 . The median wait time from first abnormal chest imaging to specialist consultation, i.e., Ti-One was 18 days (d). Ti-One was further analyzed according to the type of specialist consultation. Wait times were longest for patients who underwent a thoracic surgery consultation, with a median wait of $22 \mathrm{~d}$. Median wait time for patients who underwent a respirology consultation was similar at $20.5 \mathrm{~d}$ if the appointment occurred outside Kelowna, versus $10.5 \mathrm{~d}$ if the appointment occurred in Kelowna. 


\section{Cureus}

Patients who obtained a consultation outside of thoracic surgery or respirology (i.e. neurosurgery, internal medicine) experienced the shortest time interval, a median wait of $7.5 \mathrm{~d}$.

\begin{tabular}{|c|c|c|c|c|c|c|c|}
\hline \multicolumn{2}{|l|}{ Interval } & \multirow{2}{*}{$\begin{array}{l}\text { Median } \\
18\end{array}$} & \multirow{2}{*}{$\begin{array}{l}\text { Interquartile Range } \\
7-36\end{array}$} & \multirow{2}{*}{$\begin{array}{l}90^{\text {th }} \text { Percentile } \\
61\end{array}$} & \multirow{2}{*}{$\begin{array}{l}\text { Mean } \\
24.3\end{array}$} & \multirow{2}{*}{$\begin{array}{l}\text { Range } \\
0-181\end{array}$} & \multirow{2}{*}{$\begin{array}{l}\mathbf{n} \\
231\end{array}$} \\
\hline Ti-One & Abnormal image to specialist consult & & & & & & \\
\hline & Thoracic surgery & 22 & $10-36$ & 62.2 & 26.9 & $0-85$ & 99 \\
\hline & Respirology urban (Kelowna) & 10.5 & $5-36.3$ & 53.8 & 21.6 & $0-83$ & 68 \\
\hline & Respirology rural (outside Kelowna) & 20.5 & $7-41.8$ & 61 & 29.0 & $0-181$ & 38 \\
\hline & Other (Internal Med., Neurosurgery) & 7.5 & $2.3-20$ & 35.5 & 14.8 & $0-76$ & 26 \\
\hline \multirow[t]{5}{*}{ II-I Wo } & Specialist consult to biopsy & 9 & $3-21$ & 30 & 13.9 & $0-113$ & 231 \\
\hline & Thoracic surgery to bronchoscopy & 20.5 & $9-28$ & 35.6 & 21.8 & $0-113$ & 68 \\
\hline & Respirology (urban) to bronchoscopy & 4.5 & $1-7.3$ & 20.5 & 8.1 & $0-54$ & 44 \\
\hline & Respirology (rural) to bronchoscopy & 6 & $2-9$ & 22.4 & 8.1 & $0-30$ & 20 \\
\hline & Other specialist to bronchoscopy & 5 & $0-15$ & 19.4 & 7.6 & $0-21$ & 9 \\
\hline Ti-Three-A & Biopsy to cancer centre referral & 8 & $3-16.5$ & 40 & 14.7 & $0-126$ & 231 \\
\hline Ti-Three-B & Biopsy to lobectomy & 18 & $9-28$ & 53.2 & 24.1 & $0-92$ & 17 \\
\hline Ti-Four & Cancer centre referral to oncologic consult & 10 & $5-18$ & 24 & 11.9 & $0-47$ & 231 \\
\hline Ti-Five & Oncologic consult to first treatment & 8 & $1-15$ & 30 & 12.5 & $0-118$ & 200 \\
\hline \multirow[t]{3}{*}{ Ti-Six } & Abnormal image to first treatment & 65.5 & $41.5-104.3$ & 136.2 & 74.5 & $2-254$ & 200 \\
\hline & Palliative intent & 57.5 & $35.5-92.5$ & 131 & 67 & $2-254$ & 148 \\
\hline & Curative intent & 91 & $62-133$ & 165.2 & 96 & $10-205$ & 52 \\
\hline
\end{tabular}

TABLE 4: Time intervals for standard care pathway

\begin{tabular}{|c|c|c|c|c|c|c|c|}
\hline \multicolumn{2}{|c|}{ Time Interval } & \multirow{2}{*}{$\begin{array}{l}\text { Median } \\
9\end{array}$} & \multirow{2}{*}{$\begin{array}{l}\text { Interquartile Range } \\
4-15\end{array}$} & \multirow{2}{*}{$\begin{array}{l}90^{\text {th }} \text { Percentile } \\
21\end{array}$} & \multirow{2}{*}{\begin{tabular}{|l|} 
Mean \\
10.6
\end{tabular}} & \multirow{2}{*}{$\begin{array}{l}\text { Range } \\
0-35\end{array}$} & \multirow{2}{*}{$\begin{array}{l}\mathbf{n} \\
140\end{array}$} \\
\hline Ti-Four & Cancer centre referral to oncologic consult & & & & & & \\
\hline Ti-Five & Oncologic consult to first treatment & 7 & $1-15.3$ & 24.1 & 10.3 & $0-76$ & 140 \\
\hline \multirow[t]{3}{*}{ Ti-Six } & Abnormal image to first treatment & 55.5 & $22-89.5$ & 134.4 & 64.1 & $1-320$ & 140 \\
\hline & Palliative intent & 46 & $20-66.3$ & 102.7 & 49.8 & $1-153$ & 104 \\
\hline & Curative intent & 93.5 & $63.5-139$ & 169 & 101.7 & $7-315$ & 36 \\
\hline
\end{tabular}

TABLE 5: Time intervals for alternative clinical pathway

A median wait of $9 \mathrm{~d}$ elapsed between specialist consultation and biopsy (Ti-Two) in the form of bronchoscopy, CT-guided biopsy, or sputum cytology; if lobectomy was required, a median of $18 \mathrm{~d}$ elapsed from the time of biopsy to lobectomy (Ti-Three-B; Table 4). Subdividing the time interval from specialist consultation to bronchoscopy according to specialist type revealed a median wait-time of $20.5 \mathrm{~d}$ from thoracic surgery. By contrast, only 4.5 d elapsed from respirology consultation within Kelowna and $6 \mathrm{~d}$ if respirology consultation occurred outside Kelowna. A similar time interval ( 5 d) to bronchoscopy was observed following consultation with neurosurgery or internal medicine. A median of $8 \mathrm{~d}$ was required for pathological diagnosis and subsequent referral to the BCCA-CSI (Ti-Three-A). Once referral was received, an 


\section{Cureus}

additional $10 \mathrm{~d}$ (median) passed before consultation with either a medical or radiation oncologist (Ti-Four) and finally, a further $8 \mathrm{~d}$ elapsed before patients received their first treatment in the form of radiation and/or chemotherapy (Ti-Five). For those patients following the alternative care pathway, similar wait times were observed for time intervals Ti-Four and Ti-Five (Table 5).

Overall, the median wait time from detection of lung cancer on imaging to radiation and/or chemotherapy treatment for patients following the standard care pathway was $65.5 \mathrm{~d}$ (mean $74.5, \mathrm{n}=200$ ), or approximately 9.5 weeks (Ti-Six; Table 4). Moreover, $25 \%$ of patients waited greater than $104.3 \mathrm{~d}$. Subdividing Ti-Six by treatment intent revealed a median elapsed time of $57.5 \mathrm{~d}$ for patients obtaining palliative treatment versus $91 \mathrm{~d}$ for patients receiving treatment with curative intent. Of those patients receiving curative treatment, $25 \%$ waited longer than $133 \mathrm{~d}$ (4.5 months) and 10\% waited longer than $165 \mathrm{~d}$ (5.5 months).

The median time interval of $55.5 \mathrm{~d}$ from abnormal diagnostic imaging to first treatment (Ti-Six; Table 5) for the alternative care pathway was 10 days shorter than the standard care pathway, presumably due to the absence of a specialist consultation. This interval was reduced to $46 \mathrm{~d}$ for patients requiring palliative treatment but increased to $93.5 \mathrm{~d}$ for those requiring curative treatment.

Due to the poor prognosis associated with a lung cancer diagnosis, sufficient time had elapsed to permit assessment of overall survival within the study population. At the time of analysis, $87 \%$ and $89 \%$ of patients were deceased in the standard and alternative pathways, respectively (data not shown). Survival was calculated from the date of abnormal diagnostic imaging to the date of analysis, resulting in a median survival of $315.5 \mathrm{~d}$ for patients proceeding along the standard care pathway (Table 6 ). Patients who received palliative treatment had a considerably lower median survival ( $234.5 \mathrm{~d}$ ) than those treated with curative intent (976 d). Additionally, patients treated in the alternative care pathway had a lower median survival than patients treated in the standard care pathway ( $269 \mathrm{~d}$ versus $315.5 \mathrm{~d}$ ).

\begin{tabular}{|c|c|c|c|c|c|c|}
\hline Pathway & Median & Interquartile Range & $90^{\text {th }}$ Percentile & Mean & Range & $\mathbf{n}$ \\
\hline Standard care pathway & 315.5 & $132-698$ & 1121.3 & 473 & $30-1776$ & 200 \\
\hline Palliative intent & 234.5 & $106-416$ & 744.6 & 322 & $30-1771$ & 148 \\
\hline Curative intent & 976 & $521-1226$ & 1529.6 & 904 & $73-1776$ & 52 \\
\hline Alternative care pathway & 269 & $124-610$ & 1128.1 & 645 & $21-1617$ & 140 \\
\hline Palliative intent & 209 & $94-420$ & 800.7 & 315.6 & $21-1361$ & 104 \\
\hline Curative intent & 712 & $348-1202$ & 1410 & 759 & $56-1617$ & 36 \\
\hline
\end{tabular}

TABLE 6: Survival in days from abnormal diagnostic imaging

\section{Distance from cancer centre}

Analysis of wait times amongst the different HSDAs indicated that, in general, patients in the standard care pathway residing further from the cancer centre received treatment faster. For instance, patients residing within $20 \mathrm{~km}$ of the BCCA-CSI waited a median of $69 \mathrm{~d}$ (Ti-Six) for treatment while patients residing $>300 \mathrm{~km}$ began treatment $9 \mathrm{~d}$ sooner ( $60 \mathrm{~d}$; Table 7). Notably, this was not the case for patients in the alternative pathway, in which those residing at extreme distances, $<20 \mathrm{~km}$ or $>300 \mathrm{~km}$, experienced a shorter time interval ( $\sim 38 \mathrm{~d}$ ) than those residing at intermediate distances (60-65d). Together, these results suggest that, despite the remoteness of many communities in relation to the BCCA-CSI, rural patients, in fact, often receive care more promptly than their urban counterparts. 


\section{Cureus}

\begin{tabular}{|c|c|c|c|c|c|c|}
\hline Distance from BCAA CSI & Median & Interquartile Range & $90^{\text {th }}$ Percentile & Mean & Range & $\mathbf{n}$ \\
\hline \multicolumn{7}{|l|}{ Standard care pathway } \\
\hline$<20 \mathrm{~km}$ & 69 & $38.3-107.5$ & 140.5 & 73.9 & $6-205$ & 62 \\
\hline $20-99$ km & 66 & $43.5-105$ & 132 & 74.9 & $2-167$ & 51 \\
\hline $100-299$ km & 57 & $38.5-99$ & 132.1 & 69.6 & $3-193$ & 60 \\
\hline$>300$ km & 60 & $44-100.5$ & 133.5 & 72.9 & $10-192$ & 22 \\
\hline \multicolumn{7}{|l|}{ Alternative care pathway } \\
\hline$<20 \mathrm{~km}$ & 38 & $17.5-58$ & 101.7 & 52.8 & $12-207$ & 24 \\
\hline $20-99 \mathrm{~km}$ & 60 & $22.3-90.5$ & 125.1 & 63.2 & $7-156$ & 34 \\
\hline $100-299$ km & 65 & $40-97$ & 124 & 70.2 & $6-216$ & 41 \\
\hline$>300 \mathrm{~km}$ & 38.5 & $15.3-86.8$ & 144.2 & 60.8 & $1-320$ & 34 \\
\hline
\end{tabular}

TABLE 7: Time elapsed in days from abnormal image to first treatment according to distance from BCAA CCSI (Interior Health Patients only)

\section{Time intervals according to Health Service Delivery Area}

Generally, patients from the predominantly urban Okanagan HSDA experienced an overall time interval (TiSix) similar to the median corresponding to the care pathway undertaken (Table 8). In contrast, the small cohort of patients residing in the Northern Interior who sought treatment at the BCCA-CSI experienced the longest time interval (106 d; $n=6$ ), nearly twice that of those residing in the Thompson-Cariboo ( $57 \mathrm{~d} ; \mathrm{n}=39$ ). Surprisingly, those patients from the more remote and rural HSDAs (East Kootenay and Kootenay Boundary) exhibited contrasting results. Under the standard care pathway, a time of $95 \mathrm{~d}$ elapsed for the Kootenay Boundary patients whereas only $23 \mathrm{~d}$ elapsed for the East Kootenay patients. Interestingly, these time intervals were reversed for patients accessing the alternative care pathway, $21.5 \mathrm{~d}$ and $55 \mathrm{~d}$ for patients of Kootenay Boundary and East Kootenay HSDA, respectively. These results likely reflect the relatively small sample size for these two regions; however, they may also represent differences in the management of lung cancer patients within the two HSDAs. 


\section{Cureus}

\begin{tabular}{|c|c|c|c|c|c|c|}
\hline HSDA & Median & Interquartile Range & $90^{\text {th }}$ Percentile & Mean & Range & $\mathbf{n}$ \\
\hline \multicolumn{7}{|c|}{ Standard care pathway } \\
\hline Okanagan & 68 & $40-102$ & 138 & 74.2 & $2-205$ & 117 \\
\hline Thompson-Cariboo & 57 & $48.5-91.5$ & 117 & 71.4 & $15-193$ & 39 \\
\hline Kootenay Boundary & 95 & $50.5-133$ & 144.7 & 89.5 & $3-192$ & 24 \\
\hline Northern Interior & 106 & $98-110.3$ & 182.5 & 117.2 & $30-254$ & 6 \\
\hline East Kootenay & 23 & $21-53$ & 60.2 & 35 & $13-65$ & 5 \\
\hline Northeast & 99 & N/A & $\mathrm{N} / \mathrm{A}$ & 99 & $\mathrm{~N} / \mathrm{A}$ & 1 \\
\hline Fraser East & 138 & N/A & N/A & 138 & N/A & 1 \\
\hline Unspecified & 15 & $7.5-31.5$ & 60.2 & 26 & $6-83$ & 7 \\
\hline \multicolumn{7}{|c|}{ Alternative care pathway } \\
\hline Okanagan & 56 & $22.8-87.5$ & 122.6 & 61.6 & $7-207$ & 68 \\
\hline Thompson-Cariboo & 65 & $40-98$ & 125.6 & 71.6 & $10-216$ & 33 \\
\hline Kootenay Boundary & 21.5 & $20-38.5$ & 70.8 & 31.6 & $6-88$ & 14 \\
\hline Northern Interior & 117 & $48-134$ & 150.8 & 99.2 & $35-162$ & 5 \\
\hline East Kootenay & 55 & $12-130.3$ & 146.6 & 76 & $1-320$ & 18 \\
\hline Northwest & 48 & N/A & N/A & 48 & N/A & 1 \\
\hline Fraser North & 68 & N/A & N/A & 68 & N/A & 1 \\
\hline
\end{tabular}

TABLE 8: Time elapsed in days from abnormal image to first treatment according to Health Delivery Services Area (HSDA)

\section{Discussion}

\section{Summary of results}

Herein, we report on 200 lung cancer patients in the BC Southern Interior, diagnosed between 2010 and 2012, who experienced wait times of considerable length (median 65.5 days) between first abnormal imaging and initiation of oncologic treatment. Moreover, 25\% of patients waited longer than 104.3 days (d). Further analysis showed that patients treated with curative intent waited a median of $91 \mathrm{~d}$. Strikingly, $25 \%$ of curative intent patients waited greater than $133 \mathrm{~d}$ ( $\sim 4.5$ months) and $10 \%$ waited greater than $165 \mathrm{~d}(\sim 5.5$ months). In addition, we identified a further 140 patients who proceeded on an alternative care pathway, resulting in a slightly reduced wait time (median $55.5 \mathrm{~d}$ ), presumably due to the absence of a non-oncologist, specialist consultation following an abnormal diagnostic image.

As noted earlier, the BCCA-CSI services a geographically dispersed population. Consequently, many of the referrals must travel long distances (up to $700 \mathrm{~km}$ ) for diagnostic evaluation, specialist consultation, and oncologic treatment. Importantly, wait times for patients residing farther than $300 \mathrm{~km}$ from the cancer centre were equal to (alternative pathway) or shorter (standard pathway) than those experienced by patients residing within $20 \mathrm{~km}$ of the cancer centre, suggesting that travel distance is not a significant factor in timely access to cancer care in the BC Southern Interior.

\section{Previous literature}

Several recent studies have examined the possibility that delays in care are contributing factors to the poor prognosis of lung cancer patients [20, 22, 24, 28-29]. Although unable to provide definitive causation, these studies nonetheless present compelling evidence for the potential for wait times to adversely affect therapeutic outcomes.

The median time interval of $65.5 \mathrm{~d}$ from abnormal image to treatment initiation in this study falls well within 
the range of values of previous reports, which vary from a high of 73 to $112 \mathrm{~d}[8,14,30-31]$ in one set of studies to a low of 20 to $35 \mathrm{~d}$ in another other [20-21]. The Swedish Lung Cancer Study Group has recommended initiation of treatment within $42 \mathrm{~d}$ of abnormal imaging [32], whereas an independent report commissioned by the RAND Corporation has advocated treatment initiation within $42 \mathrm{~d}$ of diagnosis [33]. In Canada, guidelines from Cancer Care Ontario has recommended a maximum of $21 \mathrm{~d}$ from initial presentation to a general practitioner to referral to a specialist [34], with initiation of treatment within $28 \mathrm{~d}$ of a cancer diagnosis [35].

\section{Limitations and strengths}

In interpreting the results of this study, several limitations must be noted. These include the study's small sample size and higher than anticipated exclusion rate, contributing to a possible patient selection bias. In addition, an important time interval not assessed here is the time elapsed from initial symptoms to the first presentation to a medical practitioner due to a significant variability in physician records and subjectivity of presenting complaints. However, this interval constitutes a significant component of the care pathway, with delays reported from $14 \mathrm{~d}$ in Finland, $21 \mathrm{~d}$ in Ontario, and $43 \mathrm{~d}$ in the United States [23, 30, 36].

An important endpoint not addressed in this study is how overall survival correlates to wait times experienced. This parameter requires a larger study population to have sufficient power to investigate this important relationship. This will form the basis for a future province-wide study. Additionally, the delay from imaging to treatment on survival between NSCLC and SCLC subgroups could also be addressed in a future study with a larger population.

\section{Implications for practice}

Any delay between the onset of symptoms, diagnosis, and oncologic treatment may permit significant disease progression and thereby negating a subset of patients the opportunity for curative intent [8-9]. For instance, tumour size has been reported to increase by up to $373 \%$ between diagnostic and planning CT scans, constituting a median interval of $54 \mathrm{~d}$ [8], during which a fraction of patients were deemed ineligible for curative treatment. Further support comes from the finding that patients who waited greater than four months for diagnosis following an abnormal image had a worse outcome than those diagnosed sooner [9]. Together, these studies provide further support for the notion that delays in care confer a worse prognosis.

In agreement with previous studies, an interval of $43 \mathrm{~d}$ (median) from the first abnormal image to referral to BCCA-CSI suggests that most delays occur during patient diagnosis and staging [18-19]. Accordingly, previous efforts to reduce delays have targeted these areas of patient management. Through restructuring of referral patterns, a thoracic surgical centre reduced the time interval from the decision to treat to initiation of treatment from 38 to $8 \mathrm{~d}$ [37]. Similarly, a randomized controlled trial obtained a $\sim 50 \%$ reduction in time from the first presentation to treatment by devising a multidisciplinary-based treatment plan within $3 \mathrm{~d}$ of initial imaging tests and biopsy [38]. Accordingly, successful surgical resection rates more than doubled as compared to historic controls [38-39].

Perhaps the most successful interventions to date have involved streamlining the referral process. A redesign of this process featuring the addition of a nurse navigator at the Surrey Memorial Hospital termed the Rapid Autopilot Program (RAP) has reduced surgical wait times for lung cancer patients from 190 to $45 \mathrm{~d}$ [40]. Similarly, the Time To Treat Program implemented at the Toronto East General Hospital in Toronto, Ontario has enjoyed tremendous success. This latter program incorporates a clerical navigator in a streamlined referral system, reducing the time interval from suspicion of lung cancer to diagnosis from 128 to $20 \mathrm{~d}$ [ 21]. By comparison, our study revealed a median wait time from first abnormal image to cancer centre referral (assumed date of diagnosis) of $43 \mathrm{~d}$. Although, direct comparisons between studies are confounded due to differences in defining time intervals, at present patients in the BC Southern Interior continue to experience delays that may determine whether a case is surgically resectable, amenable to chemotherapy and/or radiation therapy with curative intent, or treatable by palliative measures only. For instance, $25 \%$ of patients treated with curative intent at BCCA-CSI waited greater than $133 \mathrm{~d}$ to initiate cancer treatment. Considering small cell lung cancer exhibits a doubling-time as short as 30 days, there is potential for significant disease progression during this 4.5 -month wait period.

\section{Conclusions}

We report significant time delays experienced by lung cancer patients during their cancer care path from diagnostic imaging to initiation of oncologic treatment (median $65.5 \mathrm{~d}$ ). Moreover, $25 \%$ of patients waited longer than $104.3 \mathrm{~d}$. While waiting for care, there is potential for significant disease progression, and tragically, a subset of patients may no longer be eligible for curative intent treatment. Moreover, we provide evidence that rural patients, on average, access care more promptly than their urban counterparts. This study provides data to support the need for operational change and suggests basic interventions to help reduce bottlenecks relevant to the Canadian cancer care system. 


\section{Additional Information \\ Disclosures}

Human subjects: Consent was obtained by all participants in this study. BC Cancer Agency's Research Ethics Board issued approval H13-02129. Animal subjects: All authors have confirmed that this study did not involve animal subjects or tissue. Conflicts of interest: In compliance with the ICMJE uniform disclosure form, all authors declare the following: Payment/services info: All authors have declared that no financial support was received from any organization for the submitted work. Financial relationships: All authors have declared that they have no financial relationships at present or within the previous three years with any organizations that might have an interest in the submitted work. Other relationships: All authors have declared that there are no other relationships or activities that could appear to have influenced the submitted work.

\section{Acknowledgements}

The authors thank Dr. Malcolm Paterson for thoughtful discussion during preparation of this manuscript.

\section{References}

1. Canadian Partnership Against Cancer: The 2012 cancer system performance report. Canadian Partnership Against Cancer. 2012, 1-174. Accessed: April 17, 2015: http://www.cancerview.ca/idc/groups/public/documents/webcontent/2012_system_performance_rep.pdf.

2. Howlader N, Noone AM, Karachi M, Garshell J, Miller D, Altekruse SF, Kosary CL, Yu M, Ruhl J, Tatalovich Z,Mariotto A, Lewis DR, Chen HS, Feuer EJ, Cronin KA: SEER Cancer Statistics Review, 1975-2011. National Cancer Institute. 2013, Accessed: April 17, 2015: http://seer.cancer.gov/archive/csr/1975_2011/.

3. De Angelis R, Sant M, Coleman MP, Francisci S, Baili P, Pierannunzio D, Trama A, Visser O, Brenner H, Ardanaz E, Bielska-Lasota M, Engholm G, Nennecke A, Siesling S, Berrino F, Capocaccia R; EUROCARE-5 Working Group: Cancer survival in Europe 1999-2007 by country and age:results of WUROCARE-5, a population-based study. Lancet Oncology. 2014, 15:23-34. 10.1016/S1470-2045(13)70546-1

4. British Columbia Cancer Agency: Statistics by cancer type: Lung . British Columbia Cancer Agency: facts and figures, cancer surveillance and outcomes, population oncology. 2012, 1-2. Accessed: August 5, 2015: http://www.bccancer.bc.ca/statistics-and-reports-site/Documents/Cancer_Type_Lung_2013.pdf.

5. Yang P, Allen MS, Aubry MC, Wampfler JA, Marks RS, Edell ES, Thibodeau S, Adjei AA, Jett J, Deschamps C: Clinical features of 5,628 primary lung cancer patients: Experience at mayo clinic from 1997 to 2003 . Chest. 2005, 128:452-62. 10.1378/chest.128.1.452

6. Sone S, Nakayama T, Honda T, Tsushima K, Li F, Haniuda M, Takahashi Y, Hanaoka T, Takayama F, Koizumi T, Kubo K, Yamanda T, Kondo R, Fushimi H, Suzuki T: CT findings of early-stage small cell lung cancer in a low-dose CT screening programme. Lung Cancer. 2007, 56:207-15. 10.1016/j.lungcan.2006.12.014

7. Arai T, Kuroishi T, Saito Y, Kurita Y, Naruke T, Kaneko M: Tumor doubling time and prognosis in lung cancer patients: evaluation from chest films and clinical follow-up study. Japanese Lung Cancer Screening Research Group. Jpn J Clin Oncol. 1994, 24:199-204.

8. O'Rourke N, Edwards R: Lung cancer treatment waiting times and tumour growth . Clin Oncol (R Coll Radiol). 2000, 12:141-44. 10.1053/clon.2000.9139

9. Kanashiki M, Satoh H, Ishikawa H, Yamashita YT, Ohtsuka M, Sekizawa K: Time from finding abnormality on mass-screening to final diagnosis of lung cancer. Oncol Rep. 2003, 10:649-52.

10. Quarterman RL, McMillan A, Ratcliffe MB, Block MI: Effect of preoperative delay on prognosis for patients with early stage non-small cell lung cancer. J Thorac Cardiovasc Surg. 2003, 125:108-13. $10.1067 / \mathrm{mtc} .2003 .93$

11. Liu DM, Kwee SA: Demographic treatment, and survival patterns for native hawaiians with lung cancer treated at a community medical center from 1995 to 2001. Pac Health Dialog. 2004, 11:139-45.

12. Riedel RF, Wang X, McCormack M, Toloza E, Montana GS, Schreiber G, Kelley MJ: Impact of a multidisciplinary thoracic oncology clinic on the timeliness of care. J Thorac Oncol. 2006, 1:692-96.

13. Barrett J, Hamilton W: Pathways to the diagnosis of lung cancer in the UK: A cohort study . BMC Fam Pract. 2008, 9:31. 10.1186/1471-2296-9-31

14. Gould MK, Ghaus SJ, Olsson JK, Schultz EM: Timeliness of care in veterans with non-small cell lung cancer . Chest. 2008, 133:1167-73. 10.1378/chest.07-2654

15. Baughan P, O'Neill B, Fletcher E: Auditing the diagnosis of cancer in primary care: The experience in scotland. Br J Cancer. 2009, 3:87-91. 10.1038/sj.bjc.6605397

16. Schultz EM, Powell AA, McMillan A, Olsson JK, Enderle MA, Graham BA, Ordin DL, Gould MK: Hospital characteristics associated with timeliness of care in veterans with lung cancer. Am J Respir Crit Care Med. 2009, 1:595-600. 10.1164/rccm.200806-8900C

17. Yorio JT, Xie Y, Yan J, Gerber DE: Lung cancer diagnostic and treatment intervals in the united states: A health care disparity?. J Thorac Oncol. 2009, 4:1322-30. 10.1097/JTO.0b013e3181bbb130

18. Devbhandari MP, Soon SY, Quennell P, Barber P, Krysiak P, Shah R, Jones MT: UK waiting time targets in lung cancer treatment: are they achievable? Results of a prospective tracking study. J Cardiothorac Surg. 2007, 2:5. 10.1186/1749-8090-2-5

19. Devbhandari MP, Bittar MN, Quennell P, Barber P, Krysiak P, Shah R, Jones MT: Are we achieving the current waiting time targets in lung cancer treatment? Result of a prospective study from a large United kingdom teaching hospital. J Thorac Oncol. 2007, 2:590-92. 10.1097/JTO.0b013e318070ccf0

20. Haque N, Raza A, McGoey R, Boulmay B, Diethelm L, Kantrow S: Small cell lung cancer: Time to diagnosis 
and treatment. South Med J. 2012, 105:418-23. 10.1097/SMJ.0b013e3182601198

21. Lo DS, Zeldin RA, Skrastins R, Fraser IM, Newman H, Monavvari A, Ung YC, Joseph H, Downton T, Maxwell L, Meharchand J: Time to treat: A system redesign focusing on decreasing the time from suspicion of lung cancer to diagnosis. J Thorac Oncol. 2007, 2:1001-6. 10.1097/JTO.0b013e318158d4b6

22. Cheung WY, Butler JR, Kliewer EV, Demers AA, Musto G, Welch S, Sivananthan G, Navaratnam S: Analysis of wait times and costs during the peri-diagnostic period for non-small cell lung cancer. Lung Cancer. 2011, 72:125-31. 10.1016/j.lungcan.2010.08.001

23. Ellis PM, Vandermeer R: Delays in the diagnosis of lung cancer. J Thorac Dis. 2011, 3:183-88. 10.3978/j.issn.2072-1439.2011.01.01

24. Wai ES, Mackinnon M, Hooker R, Moccia P, Perry KR, Truong PT: Wait times in diagnostic evaluation and treatment for patients with stage III non-small cell lung cancer in British Columbia. Am J Clin Oncol. 2012, 35:373-77. 10.1097/COC.0b013e3182143cce

25. Interior Health quick facts: 2014. (2014). Accessed: 2014 Sep 17: http://www.interiorhealth.ca/AboutUs/QuickFacts/Pages/default.aspx.

26. The World Bank, Data: Land area (sq. km) . (2013). Accessed: 2014 Sep 17: http://data.worldbank.org/indicator/AG.LND.TOTL.K2? order=wbapi_data_value_2013+wbapi_data_value+wbapi_data_value-last....

27. Organization for Economic Cooperation and Development: Health at a glance 2013: OECD indicators . Organization for Economic Cooperation and Development. Paris, France; 2013. 10.1787/health_glance-2013en

28. Mackillop WJ: Killing time: The consequences of delays in radiotherapy . Radiother Oncol. 2007, 84:1-4. 10.1016/j.radonc.2007.05.006

29. Canadian Medical Protection Agency: Lung cancer-the challenge of a timely diagnosis . Canadian Medical Protection Agency. 2010, 1. Accessed: August 5, 2015: https://www.cmpa-acpm.ca/-/lung-cancer-thechallenge-of-a-timely-diagnosis.

30. Salomaa ER, Sallinen S, Hiekkanen H, Liippo K: Delays in the diagnosis and treatment of lung cancer. Chest. 2005, 128:2282-88. 10.1378/chest.128.4.2282

31. Diaconescu R, Lafond C, Whittom R: Treatment delays in non-small cell lung cancer and their prognostic implications. J Thorac Oncol. 2011, 6:1254-59. 10.1097/JTO.0b013e318217b623

32. Myrdal G, Lambe M, Hillerdal G, Lamberg K, Agustsson T, Ståhle E: Effect of delays on prognosis in patients with non-small cell lung cancer. Thorax. 2004, 59:45-49.

33. Reifel J: Lung cancer. Quality of Care for Oncologic Conditions and HIV: A Review of the Literature and Quality Indicators. Asch S, Kerr E, Hamilton E (ed): RAND Corporation, London, UK; 2000. 133-172.

34. Del Giudice L, Young S, Vella E, Ash M, Bansal P, Robinson A, Skrastins R, Ung Y, Zeldin R, Levitt C: Referral of suspected lung cancer by family physicians and other primary care providers. Program in Evidence-based Care. Cancer Care Ontario's Program in Evidence-based Care (ed): Cancer Care Ontario, Toronto, Ontario, Canada; 2011. 24:2.

35. Cancer Care Ontario: Systemic treatment wait times . (2014). Accessed: 2014 Sep 16: https://www.cancercare.on.ca/cms/One.aspx?portalId=1377 \&pageId=8888.

36. Koyi H, Hillerdal G, Brandén E: Patient's and doctors' delays in the diagnosis of chest tumors . Lung Cancer. 2002, 35:53-57. 10.1016/S0169-5002(01)00293-8

37. Leary A, Corrigan P: Redesign of thoracic surgical services within a cancer network-using an oncology focus to inform change. Eur J Oncol Nurs. 2005, 9:74-78. 10.1016/j.ejon.2004.08.001

38. Murray PV, O'Brien ME, Sayer R, Cooke N, Knowles G, Miller AC, Varney V, Rowell NP, Padhani AR, MacVicar D, Norton A, Ashley S, Smith IE: The pathway study: results of a pilot feasibility study in patients suspected of having lung carcinoma investigated in a conventional chest clinic setting compared to a centralised two-stop pathway. Lung Cancer. 2003, 42:283-90. 10.1016/S0169-5002(03)00358-1

39. Laroche C, Wells F, Coulden R, Stewart S, Goddard M, Lowry E, Price A, Gilligan D: Improving surgical resection rate in lung cancer. Thorax. 1998, 53:445-49. 10.1136/thx.53.6.445

40. Lung cancer patients treated faster thanks to Surrey pilot program. Vancouver Sun . (2013). Accessed: 2014 Oct 17:

http://www.vancouversun.com/health/Lung+cancer+patients+treated+faster+thanks+Surrey+pilot+program/8263967/: 